Challenges in Argumentation and Paraphrasing Among Beginning Students in Educational Sciences

\title{
Hyytinen, Heidi
}

2017

Hyytinen , H , Löfström , E \& Lindblom-Ylänne , S 2017 , ' Challenges in Argumentation and Paraphrasing Among Beginning Students in Educational Sciences ' , Scandinavian Journal of Educational Research, vol. 61 , no. 4 , pp. 411-429 . https://doi.org/10.1080/00313831.2016.1147072

http://hdl.handle.net/10138/232986

https://doi.org/10.1080/00313831.2016.1147072

acceptedVersion

Downloaded from Helda, University of Helsinki institutional repository.

This is an electronic reprint of the original article.

This reprint may differ from the original in pagination and typographic detail.

Please cite the original version. 


\title{
Challenges in Argumentation and Paraphrasing among Beginning Students in Educational Sciences
}

\author{
Heidi Hyytinen ${ }^{1}$, Erika Löfström and Sari Lindblom-Ylänne \\ Centre for Research and Development of Higher Education, Institute of Behavioural \\ Sciences, the University of Helsinki, Finland
}

Heidi Hyytinen, heidi.m.hyytinen@ helsinki.fi, Centre for Research and Development of Higher Education, The University of Helsinki, 00014 University of Helsinki, Finland, $+358504156617$

Erika Löfström, erika.lofstrom@helsinki.fi, Centre for Research and Development of Higher Education, The University of Helsinki, 00014 University of Helsinki, Finland, $+358294120623$

Sari Linblom-Ylänne, sari.lindblom-ylanne@ helsinki.fi, Centre for Research and Development of Higher Education, sari.lindblom-ylanne@ helsinki, Centre for Research and Development of Higher Education, The University of Helsinki, 00014 University of Helsinki, Finland, +358294120628

\footnotetext{
${ }^{1}$ Correspondence concerning this article should be addressed to Heidi Hyytinen, Centre for Research and Development of Higher Education, The University of Helsinki, 00014 University of Helsinki, Finland. E-mail: Heidi.m.hyytinen@helsinki.fi
} 


\begin{abstract}
The present study aimed to identify difficulties in writing at the beginning of educational science programmes in the Finnish Open University by analysing the students' written argumentation and use of sources at the textual level. The data were analysed using qualitative content analysis. The results showed that many students began their educational studies with weak writing competencies. While many of the problems were directly related to students' failure to explain the ideas in their sources in their own words, some problems pertained to other aspects, such as the inability to construct convincing arguments. Understanding the nature of the problems in writing encountered by beginning students in educational sciences can help teachers foster students' participation in academic discourse.
\end{abstract}

Keywords: writing, argumentation, paraphrasing, higher education 


\section{Introduction}

Writing plays a central role in university learning. High-level reading and writing skills are essential for achieving high-quality learning outcomes and study success (e.g., Shaw, Mattern, $\&$ Patterson, 2011). Academic writing requires not only the necessary skills to produce texts, such as the ability to assess and integrate knowledge and make connections among ideas (Mateos \& Solé, 2009), but also necessitates an understanding of the conventions of academic writing (Lonka, 2003; Northedge, 2003; Ylijoki, 2001). Although a large and growing body of literature is devoted to how to enhance students' academic writing (e.g., Boscolo, Arfé, \& Quarisa, 2007; Simon, Erduran, \& Osborne, 2006), research on the more specific nature of the writing challenges encountered by university students is scarce.

While students are expected to live up to the expectations of academia in terms of thinking and writing competencies (Ylijoki, 2000), an increasing body of literature focuses on the challenges involved in promoting and maintaining high standards of academic writing. Easy access to information has raised concerns about how students actually use sources and refer to them, and plagiarism has been perceived as a growing problem (Gilmore, Strickland, Timmerman, Maher, \& Feldon, 2010; Park, 2003). To avoid plagiarism, students rely heavily on their sources, producing texts that merely reproduce statements rather than offer original ideas (Abasi \& Graves, 2008). Fearful of sanctions, students are unwilling to take risks (Angélil-Carter, 2000). In order to master the skill of academic writing, practice is essential, because academic language is no one's mother tongue, as Angélil-Carter (2000) points out. Teachers of academic writing need to be aware of the problems that students encounter in such matters as argumentation, paraphrasing and handling sources. A first step is to expose the nature of the challenges that students confront in their efforts to master a competence deemed vital to their university career.

We set out to analyse students' written argumentation and their use of source materials. In this study writing is operationalised in terms of how well first-year students in educational sciences at a Finnish Open University are able to conceptualise a given topic and explain it in writing on the basis of different kinds of sources. This allowed us to identify the kinds of problems that students have in constructing argumentation and in paraphrasing, and to analyse how difficulties in argumentation are related to difficulties in the use of sources, and vice versa. Although all participants were not novice in academic writing, they all were beginning students in educational sciences.

\section{Learning academic writing}

In order to become members of an academic community, students have to be socialised into both cognitive and social elements of the academic culture. Socialisation and its cultural heritage are crucial, because it helps students understand the nature of academic writing and the expectations involved (Ylijoki, 2001). Writing is a key form of communication among academics, and socialisation enables students to participate in academic discourses (Lea \& Street, 1998; Northedge, 2003).

Writing is also considered a significant tool for learning, thinking, and knowledge creation (Dysthe, 2007; Tynjälä, Mason, \& Lonka, 2001). Bereiter and Scardamalia (1987) have identified two different writing strategies: 'knowledge telling' and 'knowledge transforming'. These two strategies reflect the differences between novice and advanced writers in terms of how students bring knowledge to the writing process and how they use that knowledge. In the knowledge-telling strategy the focus is on writing down everything known about a subject, whereas in the knowledge-transforming strategy, writers show more evidence of reflective thinking during the writing process. Writers who apply the knowledge- 
transforming strategy consider carefully what to write and how to express their thoughts. Academic writing has been described as the opposite of knowledge telling (Boscolo, Arfé, \& Quarisa, 2007).

Some scholars view academic writing as a combination of reading and writing (Kruse, 2003; Mateos \& Solé, 2009). Academic writing requires particular competencies such as the ability to acquire knowledge, evaluate knowledge, integrate knowledge from different sources, explain the essence of previous knowledge in one's own words, and create a novel product by writing clearly and citing reference sources properly (Kruse, 2003; Mateos et al., 2011). Research shows that synthesising information in writing and providing reasoning based on various texts requires a knowledge-transforming strategy (Björk, Bräuer, Rienecker, \& Jörgensen, 2003; Mateos et al., 2011). This kind of writing can be challenging for a beginning writer if he or she does not yet have the necessary competences or has not been accustomed to using knowledge-transforming strategies.

Various aspects of students' competence repertoire and their prior experiences of participating in academic communities and discourse play important roles in their writing performance. A recent study has found that some students are poorly prepared for higher education (Arum \& Roksa, 2011; see also Bok, 2006), and to some extent, problems in writing can be understood as a lack of preparedness for higher education. It is possible that students are not taught to paraphrase texts or to produce convincing arguments and thus start their university studies ill-equipped. It is also possible that first-year students struggle with scientific texts because these typically include various unspoken assumptions and conventions. According to Northedge (2003), the initial problem is not a lack of knowledge, but rather unfamiliarity with academic discourse; many students simply do not have the necessary tools for interpreting a text (see also Ylijoki, 2001). Moreover, students' social backgrounds and attitudes to writing may explain differences in their learning outcomes and writing performance (Arum \& Roksa, 2011; Lea \& Street, 1998). Students' experiences and expectations of university studies also vary, which may have implications for how they approach academic writing (Ylijoki, 2001).

\section{Using sources in academic writing}

Students' problems in constructing written texts has been acknowledged in the literature on academic literacies (e.g., Street, 2004; Valentine, 2006; Kaposi \& Dell, 2012) and on plagiarism, including university students' characteristics and conceptions (e.g., Breen \& Maassen, 2005; Comas-Forgas \& Sureda-Negre, 2010; Walker, 2010; Gullifer \& Tyson, 2010) and teachers' conceptions (Sutherland-Smith, 2005; Löfström \& Kupila, 2013). According to this literature, students fear accidental plagiarism and they experience the need to try to avoid plagiarism (e.g., Gullifer \& Tyson, 2010). Their conceptions and practices may differ highly from each other (Walker, 2010), suggesting that rather than engaging in misconduct, students often struggle with mastering the social practices of their field (e.g., Kaposi \& Dell, 2012).

Previous research on beginning students has shown that they lack the competences to cite properly (Breen \& Maassen, 2005) and they are unsure about how much they should rely on sources and how to present their own ideas (Jurowska \& Thompson, 2012). While students report that they have understood what plagiarism is, it may not be common practice for them to indicate the sources utilised in their writing exercises, which suggests that there may be a substantial gap between the students' conception of their understanding and their competencies in practice (Ibid., 2012). Although many first-year students may be receptive to information about plagiarism and will be concerned about how to avoid it, there is great variability in their critical thinking and writing competencies (Darab, 2006). 
Gilmore et al. (2010) demonstrated that a large number of students in engineering and the natural sciences copy-pasted texts into their research proposals from websites without mentioning the source or any primary literature, or they failed to cite their sources correctly. In addition to verbatim copying, Walker (2010) has also identified other problems in referencing: 'sham' in which a student correctly cites a source but presenting the material as paraphrased, when in fact a text is a direct quote without the quotations marks, and 'purloining' in which a student copies the work of another student. However, such writing strategies may not always be used with the intention to deceive. Authors in the area of academic literacies emphasise that "patchwriting" is often a central writing strategy in the development towards a competent writer, and the use of these strategies denotes that the student is trying to come to grips with the discourses of their disciplines (Kaposi \& Dell, 2012). Cameron et al. (2009) have shown that scientific writing courses, which address the structure of a manuscript and the ethics of writing, have proven successful in improving students' writing and in raising their confidence as writers, suggesting the evolving nature of academic writing competencies and the need for continuous support in developing them.

\section{Argumentation in academic writing}

An effective argument convinces a listener or a reader. Argumentation, especially the tradition of written argumentation, has had an essential role in academic discourse (Keinonen \& Kärkkäinen, 2010; Rapanta, Garcia-Mila, \& Gilabert, 2013). The term 'argument' is traditionally defined as "an attempt to present evidence for a conclusion by providing claims that support the conclusion" (Groarke, 2013, para.9).

Previous studies on argumentation include a range of different perceptions. Research has concentrated, for instance, on exploring how classroom argumentation practice enhance to conceptual change (e.g., Nussbaum, Sinatra, \& Poliquin, 2008; Sandoval, 2009), assessing the teaching of argumentation (e.g., Simon, Erduran, \& Osborne, 2006) and exploring connection between cognitive or epistemological development and argumentation (e.g., King \& Kitchener, 2004; Kuhn 1999; 2005; Kuhn \& Weinstock, 2002). In earlier academic writing studies (e.g., Keinonen \& Kärkkäinen, 2010; Simon et al., 2006) argumentation has often been analysed by applying Toulmin's (1958) framework, which indicates three necessary parts of an argument. These are the claim, the support, and the warrants. In a solid argument, claims warrant "conclusion by providing good reasons for them" (Siegel \& Biro, 1997, p. 278). Furthermore, argumentation can be analysed through fallacies of argumentation (Walton, 1995). Fallacies refer to errors in reasoning: the rationales given do not support the conclusion.

Previous studies have shown that higher education students have several problems in producing arguments, paraphrasing and utilising knowledge from different sources. For example, science students have been found to draw on personal feelings instead of scientific knowledge in their argumentation (Keinonen \& Kärkkäinen, 2010). Students may also harbour the view that data should be explained or 'told' rather than analysed (Sandoval, 2009; cf. Hyytinen, Nissinen, Ursin, Toom, \& Lindblom-Ylänne, 2015). Students have been shown to use data to generate claims, but fail to regard data as a necessary component in the construction or substantiation of an argument Hyytinen, Holma, Toom, Shavelson, \& Lindblom-ylänne, 2014; Hyytinen et al., 2015). Simultaneously, the students did not appear to consider the lack of confirming evidence for their claims as potential counter-evidence that could call the claims into question (Ibid., 2009). Previous research has also suggested that students' reasoning and writing skills do not always develop during their university studies (Arum \& Roksa, 2011; see also Bok, 2006; Pascarella \& Terenzini, 2005).

A recent review study has shown that previous research in education has focused on students' ability to assess already produced arguments rather than students' ability to produce 
their own arguments (Rapanta et al., 2013). The present study responds to this need by exploring students' written argumentation. The aim of the study is to deepen the understanding of the challenges in argumentation and paraphrasing as they emerge in writing among beginning students in educational sciences. By revealing what kind of challenges students face, the study will help to shed light on why students' gains in written communication might remain modest.

We focused on common problems identified in the review of the literature, such as problems using sources and constructing solid arguments and have attempted to understand how paraphrasing and argumentation are problematic for university students. Even though there are many field-specific conventions in academic writing, it is possible to also identify commonalities of texts at the micro level: we can analyse the construction of a solid argument (cf. Walton, 1995; Siegel \& Biro, 1997) and the nature of paraphrasing of sources if we have the original source at our disposal. By analysing qualitative differences in argumentation and paraphrasing, it is possible to identify when and where university teachers need to intervene. Strategies that support different writers can then be identified. As stated previously, there are myriad of factors related to and influencing academic writing, such as institutional procedures, field-specific conventions, students' prior knowledge, expectations, and social background (Arum \& Roksa, 2011; Lea \& Street, 1998). Many of these factors individual teachers have little or no influence over. Therefore, we have chosen to focus specifically on aspects of academic writing that every university teacher can address in their teaching. We posed the following question: How do challenges in argumentation and paraphrasing manifest themselves in the writing of students?

\section{Method}

\section{Context}

The context for our study was a Finnish Open University. Open Universities are part of the Finnish university system. Almost all Finnish universities provide Open University education in co-operation with their departments and faculties. Open Universities are thus not autonomous universities. They offer university-level studies for everyone, regardless of age or educational background. The course contents and the criteria for assessing learning outcomes are equivalent to the teaching at the affiliated university. However, Finnish Open Universities do not award academic degrees. In the year 2011, over 43,000 participants attended Open University courses in Finland (Statistics Finland, 2012). Many Open University students are adults who want to develop themselves in general or expand their knowledge in a specific subject. Another group of Open University students consists of graduates of upper-secondary school who seek to improve their opportunities to gain university entrance either by taking courses in the subject they hope to study or by studying a set of basic level courses that provides an alternative route to university studies. For instance educational sciences offer such an alternative route.

\section{Participants}


The participants were 138 new students in educational sciences (117 women and 21 men) attending a Finnish Open University. These students had heterogeneous educational backgrounds: 23 per cent of the participants had university degrees (a bachelor's, master's, or doctoral degree); 36 per cent had a polytechnic degree; $16 \%$ had completed vocational uppersecondary education; and 25 per cent had a general upper-secondary education before undertaking educational sciences studies. Thus, not all students were beginning students in the sense that they were unfamiliar with university studies. However, all students were beginning students in educational sciences. The students' ages varied from 20 to 64, the mean age being 35. Although women were over-represented in the sample, the distribution was representative of the university population in Finland: three-fourths of Open University students are women (Statistics Finland, 2012).

\section{Data collection}

All new students in educational sciences were invited to participate in the study and $48 \%$ of the cohort volunteered. The students gave their written consent for participation, and they were informed that consenting or refraining from consenting would not affect their status or subsequent grades in any way. Incentives were not used. Students were also informed that they would not receive individual feedback of their performance. However, the purpose was to collect baseline data about incoming students' writing competencies. Based on this data, necessary interventions can be fed into subsequent courses. The data were processed in such a way that the participants could not be identified.

The students' writing was assessed using the constructed-response task of the Collegiate Learning Assessment (CLA). The task was translated and adapted to a Finnish context. The CLA task is designed to measure general academic skills, such as critical and analytical thinking, problem-solving, and written communication (Arum \& Roksa, 2011; Klein, Benjamin, Shavelson, \& Bolus, 2007; Shavelson, 2010). The CLA task requires students to apply critical thinking and written communication skills. The task used in this study simulated academic writing processes and included instructions, four open-ended questions, and reading material about a fictitious, but realistic societal problem (see Figure 1). In order to respond, the students needed to (a) organise, synthesise, assess, and analyse information (which might be reliable/unreliable or relevant/irrelevant to the task); identify judgmental errors, such as 'correlation proves causation' from seven sources (memoranda, research abstracts, research report, newspaper story, several tables and statistics); (b) make a reasoned explanation for a problem and propose a solution; and (c) write arguments and counter-arguments for and against a particular solution using information from the reading material (Shavelson, 2010). The length of the reading materials ranged from a chart with a title of 20 words to a text comprising 470 words. Students had 90 minutes to complete the task. The instructions explicitly advised students to cite sources as well as to justify their positions. The constructed-response task used in this study is proprietary and consequently cannot be described in further detail here. We have employed the CLA task in our previous studies (Hyytinen et al., 2014; Hyytinen et al., 2015).

The strengths and limitations of constructed-response tasks have been debated extensively (e.g., Attali, 2014; Bowman \& Seifert, 2011; Hyytinen et al., 2015; Popham, 2003; Shavelson, 2010; Rodriguez, 2003). In the constructed-response tasks students create their own answers, making it possible to analyse the level of understanding and processing (Hyytinen et al., 2015; Popham, 2003; Rodriguez, 2003). The constructed-response task are described as authentic assessment because these task demonstrate the same thinking processes that individuals use when they solve complex problems in their daily lives (Andrew \& Wulfeck, 2014; Baartman, Bastiaens, Kirschener, \& van der Vleuten, 2007). However, disadvantages of 
the constructed response task have been reported. For example, assessing bias (e.g., a lack of consistency) is a potential concern, because students' written answers are assessed by human evaluations (Almond, 2014). Difficulties may especially arise if researchers do not ensure that assessing criteria are used in a systematic way. Therefore, the scorers are trained to assess students' test responses. Another criticism concerns the focus of the tasks. It is assumed that one assessment method or task cannot completely capture the complexity of cognitive processes such as reasoning (e.g., Baartman et al., 2007; Maclellan, 2004; Hyytinen et al., 2015). The CLA task is criticised because of its generality: the questions and other materials in the CLA task are not specialised to the specific context. However, it ensures that the task could be completed by students from a variety of disciplines. Therefore, it is possible to collect data across samples in the different fields. The validity of CLA task is discussed more deeply by Shavelson (2010) as well as Arum and Roksa (2011).

Insert Figure 1 here

\section{Analysis}

The data were analysed using qualitative content analysis. The analytical process was divided into four phases (see Figure 2). In the first phase, the first and second authors read the students' texts through several times independently to obtain a sense of the whole and make notes on relevant information. Thereafter, the definition of coding features was negotiated jointly. In the second phase, the first author coded the data using the ATLAS.ti programme. This phase was theory-driven, meaning that the features of coding were based on prior studies. In order to identify problems in paraphrasing and citing references and fallacious arguments, we used the referencing problems identified by Walker (2010) and the argumentation schemes defined by Toulmin (1958) and Walton (1995). Furthermore, we utilised our previous findings of thematic analysis (Hyytinen et al., 2014). Coding concentrated on the following aspects: (1) problems in argumentation (i.e., reasons and claims that student uses as evidence are not consistent with the conclusion) and (2) problems in paraphrasing (i.e., student does not explain a passage from source materials in his or her own words). These different aspects were systematically coded within each written answer. In addition, students' answers were carefully compared with the source materials. The credibility of the coding was checked by the second author, who coded 25 per cent of the data. Consistency of coding between the first and second author was 95 per cent. The first author considered the suggested changes and changed the coding where appropriate.

In the third phase, we grouped codes into categories and sub-categories. Thereafter, the categories were refined, labelled and cross-checked in relation to the entire data set. The occurrence of the categories through the data set was also examined. The abstraction process and the final categories are described in Table 1. Altogether we identified three categories of problems in argumentation and five categories of paraphrasing problems (as explained below). In the last phase, students' written answers were classified into three groups on the basis how students had processed the available source materials and how coherent the answers were. After that, the differences between and within the groups were examined. The final results and interpretations were obtained through discussion with the authors in order to guarantee agreement between the researchers and to assure the reliability of results. The authors analysed the data in their original language and finally translated the data extracts chosen to illustrate the results into English. 
Insert Figure 2 here

\section{Findings}

\section{Problems in argumentation}

We identified three main problems in argumentation, which we labelled 'unclear argumentation', 'isolated facts', and 'incorrect arguments/fallacies' (see Table 1). In 'unclear argumentation', substantial claims or reasons that support the conclusion were missing, thereby leaving the argument obscure or lacking in logic. 'Isolated facts' refers to a situation in which students provided only a single reason or rationale in cases of parallel or competing reasons, offered disconnected or random facts, and connected these to each other without proper justification. 'Fallacy/incorrect argument' refers to errors in reasoning: students drew a conclusion, but the rationales given did not support the conclusion. The fallacies were hasty generalisations, i.e., a student argued from a special case to a general rule based on insufficient evidence; an irrelevant conclusion, i.e., a student used irrelevant information as evidence; a correlation proved causation, i.e., a student argued that a correlation implied causation. Incorrect arguments also included appealing to authority, tradition, or probability rather than a solid argument based on the careful analysis of the information provided. In 'appealing to authority', a student argued that something was true or correct because an authority on something had asserted it was so. Appealing to authority is not necessary fallacy: this kind of arguments can be judged as fallacy and sometimes not depending on the situation. The question is, whether "the authority is a good one (for the conclusion in question)" (Siegel \& Biro, 1997, p.286). In this case the authority was nominally competent, but the problem was that the argument from authority was biased and thus not relevant to the question. In 'appealing to probability', a student took something for granted because it would probably be true, whereas in 'appealing to tradition' a student argued that something was true or correct because it correlated with tradition.

\section{Problems in paraphrasing}

We identified five types of paraphrasing problems, namely 'copy without source', 'copy with source', 'poor paraphrasing', 'patchwork paraphrasing', and 'conclusions disguised as one's own'. 'Copy without source' refers to a situation in which a student copied short portions of a source text without a source citation. 'Copy with source' refers to situations in which a student cited a source, but presented the material without quotation marks as if it were paraphrased, when in fact the student had copied the material word-for-word. In 'poor paraphrasing', a student properly cited the sources, but changed and modified a source text slightly, for example, by changing or adding words or using synonyms. Poor paraphrasing appeared to include minimal or no processing of the materials. In 'patchwork paraphrasing', a student pieced together small parts of poorly paraphrased or directly copied texts from several sources and possibly some own formulations. In patchwork paraphrasing some relevant processing of the materials may have occurred. 'Conclusion disguised as one's own' refers to a situation in which a student paraphrased conclusions from the materials without a citation, giving the impression that the conclusions were the result of the student's own analysis. 
Insert Table 1 here

\section{Qualitative differences in the texts}

The specific types of problems in writing and the ways in which the problems were related to each other differed among the participants, which allowed us to identify the nature of the problems encountered by the students. We identified three text groups and, on the basis of their characteristic features, labelled the groups 'superficially processed texts', 'patchy texts', or 'thoroughly processed texts'. These three groups characterise how students have used and processed the available source materials; they also illustrate how coherent and organised the students' written answers were. In addition the groups captured the diversity of the problems in academic writing, including problems in argumentation and citing references.

The group 'superficially processed texts' contained answers in which the students did not present evidence of their own understanding or processing of the materials. In the group labelled 'patchy texts' the answers were uneven in quality. In the group labelled 'thoroughly processed texts', the written answers demonstrated a deep processing of the materials. These answers were also organised in a cohesive way.

Insert Table 2 here

Table 2 shows how many students in each group struggled with each specific problem in argumentation and paraphrasing. There were substantial differences in how the categories and their frequency varied among the groups. For example, in the group 'thoroughly processed texts', we identified only three problem categories in paraphrasing, and the frequencies were low, whereas we identified five problem types in the two other groups (i.e., 'superficially processed texts' and 'patchy texts'), and the frequencies were much greater. In the groups 'superficially processed texts' and 'patchy texts' the problems tended to repeat, whereas in the group 'thoroughly processed texts', the problems tended to be merely isolated occurrences. The problems identified in argumentation and paraphrasing are prevalent in all groups, but are fewer among students who wrote thoroughly processed texts compared to the two other groups of writers. Below we describe in more detail the characteristics of the three text groups and provide details pertaining to each problem category.

\section{Superficially processed texts}

One-third ( $\mathrm{n}=46)$ of the students' answers belonged to this group in which students did not present evidence of their own understanding or processing of the materials. Moreover, the answers were very short in comparison to the other two groups, the texts varying in length from one or two sentences to a short paragraph. Some students had disregarded much of the information presented there and used only one or two sources in each writing task. It was often unclear which sources the students had used. The answers were typically composed of reproduced and isolated details or the entire answer was based on the writer's opinion, that is to say, the students did not follow instructions and did not use the sources.

The following extract describes a typical response in the superficially processed text group. When the student has copied or slightly altered portions from the task materials without quotation marks we have indicated it by underlining those segments.

Question 1: 
Dr. Eager claims that Major Stone's proposal "will lead to more crime" (Document E contains the chart Dr. Eager used to support this claim). What are the strengths and/or limitations of Dr. Eager's position on this matter? Based on evidence, what conclusion should be drawn about Dr. Eager's claim? Why? What specific information in the documents led you to this conclusion?

\section{Student:}

I disagree. Increasing the number of police officers will not lead to more crime.

Common to all the texts in this group was that the arguments were often vague, and paraphrasing was insufficient. The answers contained several problems in argumentation and referencing. Moreover, the same problems recurred numerous times. We identified all three categories of argumentation problems: making unclear arguments, presenting isolated facts as rationales and using incorrect arguments/fallacies. A typical problem was an unclear argument: two-thirds of the students in this group stated conclusion, but failed to give a rationale or reason (see Table 2). Other students provided rationales, but did not clearly state what the rationale was for. More than one-third (41\%) of the students from this group provided a single reason in cases of parallel or competing reasons or presented a disconnected list of facts as rationales. The third category was fallacy: two-thirds of the students produced fallacious arguments. The fallacies were 'hasty generalisation', 'irrelevant conclusion', 'correlation proves causation' and 'appeal to probability'.

The analysis further indicated several problems in paraphrasing material from sources. A frequent problem was poor paraphrasing: although the students often gave the correct source, they slightly altered the passage by changing words or using synonyms. Thus, the texts were almost the same as in the original. Further, over half of the students correctly cited from a source, but presented the material without quotation marks as if it were paraphrased, when in fact arguments or short portions had been copied word-for-word from the source materials. On the other hand, six students (13\%) in this group copied arguments and short portions of text from the materials without quotation marks or a source reference. We also identified patchwork papers in which students had pieced together poorly paraphrased or directly copied texts. A few students paraphrased conclusions from their sources without any citation, giving the impression that the conclusions were the results of their own thinking.

\section{Patchy texts}

The second group of student answers was labelled 'patchy texts'. This was the largest group in terms of frequency $(n=73)$. The answers demonstrated that the students in this group had apparently made an effort to understand the source materials, had presented somewhat relevant information from the materials and also provided their own ideas, but failed to weave these aspects into convincing arguments. The answers were often incoherent. Furthermore, answers often contained reproduced or slightly modified portions of passages from the source texts. Students also made many misinterpretations of the information in the materials. They especially struggled with interpreting statistical information. Some students used colloquial language rather than academic expressions. Some students were not able to distinguish relevant claims from irrelevant ones: they provided conflicting claims, but did not compare or analyse the claims or reasons behind them, nor did they draw any conclusion as to what option would be desirable and why.

The following extract from one student's answer describes a typical text in this group. When the student has copied or slightly altered portions from the task materials without 
quotation marks we have indicated it by underlining those segments. Furthermore, when the student has misunderstood the task materials and presents argument based on those misunderstandings we have indicated it by italicising those segments.

Question 1:

Dr. Eager claims that Major Stone's proposal "will lead to more crime" (Document E contains the chart Dr. Eager used to support this claim). What are the strengths and/or limitations of Dr. Eager's position on this matter? Based on evidence, what conclusion should be drawn about Dr. Eager's claim? Why? What specific information in the documents led you to this conclusion?

\begin{abstract}
Student:
Pat Stone, Mayor of Jefferson, proposes increasing the number of police officers for reducing crime. Stone is running for reelection as mayor and her opponent is Dr. Jamie Eager. Eager disagrees with Stone's proposal for increasing the number of police officers in order to reduce crime. According to Eager, increasing the number of police officers will only lead to more crime. Eager supported this argument with a chart showing that counties with relatively high number of police officers per resident tend to have more crime than those with fewer officers per resident. According to the chart, for example, in the counties where there are only 2 police officers per 1000 residents, the number of robberies and burglaries is only 4. By contrast, in the counties where there are 9 police officers per 1000 residents, the number of robberies and burglaries is as much as 95.

Eager seems to be correct in that the greater the number of police officers per resident the more there is crime. Therefore, Eager proposed that we should take the money that was meant for hiring more police officers and spend it on the Strive drug-treatment program. Eager supported his argument by the information that most of the individuals who have been arrested for robberies and burglaries were drug users. For example, according to the tables from the Jefferson Police Department, $60 \%$ of the offenders were drug users. The table shows that at least 35\% of the offenders were drug users. This is a matter of high percentages, therefore I agree with Eager's argument that the number of crimes will decrease with the drug treatment.
\end{abstract}

In this group the texts were characterised by vague arguments and insufficient paraphrasing and contained various problems in argumentation and referencing. The same types of problems recurred in the students' texts, indicating that if a student struggled with a certain kind of problem, it tended to persist (see Table 2). Again, in the analysis all three categories of argumentation problems were identified: two-thirds of the students in this group provided unclear argumentation, one-fourth presented isolated facts as rationales, and threefourths presented incorrect arguments/fallacies. We identified six different sub-categories of incorrect argument. The most common was an irrelevant conclusion. In these texts students tried to use irrelevant viewpoints or misinterpretations as evidence. Some students also made hasty generalisations, and some assumed that correlation proves causation. Furthermore, we also identified appealing to authority, appealing to probability, and appealing to tradition.

In this group a typical problem was insufficient paraphrasing. More than 80 per cent of the students did not explain the content or idea of the borrowed materials in their own words: they just modified the source text slightly. Two-fifths of the students cited a passage from a source correctly, but presented the material without quotation marks as if it were paraphrased, when in fact arguments or short portions had been copied word for word. Furthermore, some students copied short portions of text from the source materials without quotation marks or 
identifying the source. A few students also used patchwork paraphrasing or disguised conclusions as their own, i.e., presenting the paraphrased materials as if it was the result of their own analyses of the materials.

\section{Thoroughly processed texts}

In the group 'thoroughly processed texts' the answers $(n=19)$ were characterised by pertinent argumentation and substantial paraphrasing. These answers indicated a deep processing of the materials, used clear wording, and showed that the students had understood the major issues. The students had identified most of the core ideas presented in their sources. They provided valid and comprehensive elaboration on key facts or ideas related to each argument and identified their sources of information clearly. The students were able to distinguish relevant claims from irrelevant ones: they gave reasoned explanations, weighed different options, and explained what option/explanation was to be preferred and why. The students wrote an organised text, connected related ideas, and made the connections clear. The written answers in this group were the least typical (14\%). The small percentage of thoroughly processed texts indicates that only a small number of beginning students in educational sciences who participated in this study was able to produce texts without some level of difficulties.

The following extract describes a typical response in the thoroughly processed text group. When the student has misunderstood the task materials and presents reasons based on those misunderstandings we have indicated it by italicising those segments.

Question 1:

Dr. Eager claims that Major Stone's proposal "will lead to more crime" (Document E contains the chart Dr. Eager used to support this claim). What are the strengths and/or limitations of Dr. Eager's position on this matter? Based on evidence, what conclusion should be drawn about Dr. Eager's claim? Why? What specific information in the documents led you to this conclusion?

\section{Student:}

I do not unconditionally agree with the candidate Eager that "increasing the number of police officers will lead to more crime". His statement is based on statistics (document E), which describe the number of robberies and burglaries per 1000 residents. This chart indeed shows that the number of robberies and burglaries is higher within the areas in which there are more police officers, but the chart indicates neither the total amount of crimes nor whether the robberies and burglaries are related to crimes following from the use of drugs. Furthermore, we do not know how Jefferson rates on the list of the 53 biggest counties, nor if it rates at all. However, it is known (document B) that a part of the robberies have been associated with the drug problem churning in this area. Eager has received information from the police (document F), which describes a relationship between the number of crimes committed and drug use in Jefferson. However, he did not use this document to support his claim, but this document reveals the relationship, that is, where the number of adult drug users is higher, there are more documented robberies and burglaries. However, we do not know what the numbers of police officers within the different areas are, and this is essential information when we consider the different alternatives. Considering these aspects, in my opinion, Mayor Stone should explore at the national level if Jefferson has had the same kind of problems as other comparable counties, and based on this 
investigation she should explore if Eager's proposal is beneficial considering the problem.

Although the answers in this group demonstrated relatively good writing competencies, the students still had some difficulties in argumentation and paraphrasing. The most usual type of problem was an incorrect argument: almost half the texts contained one or two incorrect arguments; one-fifth contained unclear argumentation and one-fifth involved using isolated facts as rationales. In this group we identified two sub-categories of incorrect arguments, namely hasty generalisations and irrelevant conclusions. Without exception irrelevant conclusions pertained to situations in which the students had misinterpreted statistical information. None of the students in this group maintained that correlation proves causation, nor appealed to probability, authority, or tradition. In contrast to the other two groups, problems in argumentation or paraphrasing did not reappear in the students' answers in this group.

Students typically began with one or two sentences, giving the main points from the source materials, after which they summarised the content in their own words, adding synthesising thoughts and ideas of their own. Almost all paraphrasing problems appeared in the first 'main points' sentences, most of which were copied or insufficiently paraphrased from the source materials. In this group copying or poor paraphrasing occurred at the beginning of an answer, that is, the students copied a passage to initiate a starting point or claim, but quickly reverted to their own text.

In this study students' educational backgrounds and gender were relatively evenly distributed among the groups. As Table 3 shows, the students' educational background was not related to their performance in academic writing. The only exceptions were students with a vocational education. Half of the participants who had completed vocational secondary education wrote texts that were placed in the 'superficially processed texts' group.

Insert Table 3 here

In sum, the aspects that differentiated the text groups were 1) the frequency of problems, 2) the combination of different types of problems, 3 ) the location of problems within the text, and (4) the length of the texts.

\section{Conclusions}

Writing is an act of meaning making and advancing thinking (Tynjälä et al., 2001; Dysthe, 2007). It is also clear from our data that problems in thinking and problems with writing were related. The results of this study showed that the nature of the difficulties and their variance among groups were interlinked with the students' ability to utilise and process the available materials. These results corroborate those of our previous studies (Hyytinen et al., 2014, Hyytinen et al., 2015). Fallacies and incorrect arguments were prevalent in all groups, but these were fewer among students who wrote thoroughly processed texts as compared to the other two groups of writers. Students in the group exhibiting the superficially processed texts had trouble with argumentation and using sources properly, poor paraphrasing and copying being frequent problems. The students who wrote patchy texts, but apparently made an effort to understand the sources also had problems with unclear argumentation and, to some extent, with using sources and explaining the content of the materials in their own words. 
It is important to recognise that even the students who wrote thoroughly processed texts had trouble with paraphrasing. However, this problem was qualitatively different among the students in this group compared to the students in the groups 'superficially processed texts' and 'patchy texts'. In the 'thoroughly processed texts' group, poor paraphrasing occurred mostly at the beginning of an answer and appeared to be a strategy for 'getting started'. This means that the students attempted to synthesise the information in the sources, but in doing so, managed to modify the original texts slightly instead of truly synthesising the information in their own words. Perhaps this problem is also indicative of a lack of process writing; i.e., the texts improved as the students went along, but the students did not return to their starting sentences to revise them to the same standard as the subsequent texts. Another reason might be that the limited time frame prevented the students from making full use of process writing by rewriting paragraphs. Apparently, paraphrasing is a step towards writing mastery, but the students still struggled with how to use their sources.

Higher education has been identified as a suitable context in which to facilitate the learning of argumentation (Rapanta et al., 2013). However, we know from prior research that not all higher education students are particularly skilled writers (Gilmore et al., 2010; Mateos \& Solé, 2009) or competent at producing arguments (Keinonen \& Kärkkäinen, 2010; Sandoval, 2009). Our study identifies the nature of the problems, both in paraphrasing as well as in constructing and sustaining an argument. While many of the difficulties were directly related to the lack of sufficient writing competencies, resulting in different types of referencing faults, some pertained to other incompetencies, such as the failure to construct a valid argument or logical rationale. The results also revealed that the majority of the student participants had trouble interpreting statistical information. This finding is surprising, given that 60 per cent of the participants reported having a tertiary education degree.

Present study identifies the anatomy of the problems in writing pinpointing in detail what the problems are. In this way it contributes to the literature on academic literacies, which views writing as social practice, and on plagiarism, which often (but not always) views writing from the perspective of moral problem and transgression. While it is necessary to understand learning to write as a process of socialisation into an academic field and to recognise the borders of convention, creativity and transgression, it is equally important to identify precisely what those problems de facto are in order to understand the relationship between socialisation as learning and ultimately mastering those practices. Through the challenges manifested in novices' argumentation and use of sources, it is possible to understand the beginning pathways in socialisation through writing.

Half of the cohort consented to participating in the research, which can be considered a relatively high percentage. However, the level of academic writing skills of those students who either declined to participate in the test or those who did not give their consent remains unknown. It is possible that the students who agreed to participate in the research were more academically inclined compared to those who did not and felt more confident with their test performance and writing skills. This suggests that the difficulties with which students struggle may be greater than our study indicates. On the other hand, although all participating students were volunteers, students completed only one ninety-minute writing task. It is thus possible that a certain aspect of test situation (such as life situation, activity level, mood) may have affected students' written responses. For example, we do not know with how sincere an effort they completed the task. However, we have identified similar problems in the students' writing in our previous studies (Hyytinen et al., 2014; Hyytinen et al., 2015). In these studies students have reported that they have done their best or close to their best to complete the constructedresponse task. Additionally, one reason for the low performance of some students might be that the task with an ill-structured problem differed from tasks encountered in their previous studies. It is also possible that students were not aware of how argumentation and paraphrasing are 
understood in academic discourse and what is demanded from the solid argument (cf. Lea \& Street, 1998; Northedge, 2003). The results therefore need to be interpreted with caution. In future studies on academic writing skills, it may be fruitful to investigate writing performance in relation to the students' expectations of academic writing.

Although students' texts provided a potential arena for identifying problems in writing, the findings of this study should not be generalized as an accurate prediction of the target population. Rather the findings of this study illustrate the challenges in writing in a specific task. In order to determine the extent to which findings can be transferred to other types of tasks or even other student populations, research efforts need to be geared towards expanding the types of tasks and other groups of students. Moreover, we only rely on authentic assignment data, and thus we do not know what the students were thinking about the task and the writing, and why they made the choices they made. Understanding how students think and reason would, however, be important from the perspective of learning process. Therefore, further studies on the current topic are recommended.

\section{Pedagogical implications}

Open University students are a remarkably heterogeneous group. They enter higher education with widely varying skills in academic writing, and they are expected to begin developing these skills and learning the proper conventions from the very beginning of their studies by means of different writing assignments. Studies in educational sciences often involve substantial writing, including essays, short reports, learning diaries etc. Because there was substantial variation in the students' writing competencies, it is clear that a 'one-size-fits-all' model of teaching is inadequate. The students with the most problems in their writing would benefit from instruction supporting their academic writing competencies, starting from how to use sources, how to refer to them properly, and how to summarise the content of materials in their own words. We know from prior research that students express frustration over the difficulty in learning to write academic texts (Gu \& Brooks, 2008). While our study did not address the students' emotional reactions to writing, it is possible that students with numerous problems in their writing also suffer from low self-efficacy as writers and harbour negative feelings in relation to writing. These students may benefit from support in attending to the emotions of writing (cf. Cameron, Nairn \& Higgins, 2009). All beginning students, including those with relatively few problems in their writing, would benefit from instruction and practice in clear expression and in the characteristics of a well-structured and well-presented argument. It appears that the competent writers already handle their sources confidently and would benefit instead from encouragement to experiment with their own 'voice'. Previous studies have shown that students are unwilling to take risks and prefer to reproduce the source materials rather than present their own ideas (Abasi \& Graves, 2008; Angélil-Carter, 2000). However, university teachers play an important role in promoting students' awareness of values and norms in academic writing. Good practices of argumentation and referencing are aspects of academic writing that every university teacher can pay attention to in students writing and facilitate in their teaching. By doing so, teachers can foster students' participation in academic discourse.

\section{Acknowledgements}

The first author was financially supported by a scholarship from the Alfred Kordelin Foundation. This work was supported by the Academy of Finland under Grant 252813 to the second author. We are grateful to Roger Benjamin at the Council for Aid to Education for 
permitting us to use and reproduce a performance task from the Collegiate Learning Assessment, and to Taina Lehtinen (Licentiate in Social Sciences), Saara Repo (Ph.D) and Erja Rusanen (Ph.D in education) for helping us in data collection.

\section{References}

Abasi, A. R., \& Graves, B. (2008). Academic literacy and plagiarism: conversations with international graduate students and disciplinary professors. Journal of English for Academic Purposes, 7, 221-233.

Almond, R. G. (2014). Using Automated Essay Scores as an Anchor When Equating Constructed Response Writing Tests. International Journal of Testing, 14, 73-91.

Andrews, D. H., \& Wulfeck H. (2014). Performance Assessment: Something Old, Something New. In J. M. Spector, M. D. Merrill, J. Elen, M. J. Bishop (Eds.), Handbook of Research on Educational Communications and Technology (pp. 303-310). New York: Springer.

Angélil-Carter, S. (2000). Stolen language? Plagiarism in writing. London: Pearson Education.

Arum, R., \& Roksa, J. (2011). Academically Adrift. Limited Learning on College Campuses. Chicago: The University of Chicago Press.

Attali, Y. (2014). A Ranking Method for Evaluating Constructed Responses. Educational and Psychological Measurement online, DOI: 10.1177/0013164414527450

Baartman, L. K. J., Bastiaens, T. J., Kirschner, P. A., \& van der Vleuten, C. P. M. (2007). Evaluating assessment quality in a competence-based education: A qualitative comparison of two frameworks. Educational Research Review, 2, 114-129.

Bereiter, C., \& Scardamalia, M. (1987). The psychology of written composition. Hillsdale, NJ: Lawrence Erlbaum Associates.

Björk, L., Bräuer, G., Rienecker, L., \& Jörgensen, P. S. (Eds.). (2003). Teaching Academic Writing in European Higher Education. Studies in Writing. Dorchrecht: Kluwer Academic Publisher.

Bok, D. (2006). Our underachieving colleges. A candid look at how much students learn and why they should be learning more. Princeton, NJ: Princeton University Press.

Boscolo, P., Arfé, B., \& Quarisa, M. (2007). Improving the quality of students' academic writing: an intervention study. Studies in Higher Education, 32 (4), 419-438.

Bowman, N. A., \& Seifert, T. A. (2011). Can College Students Accurately Assess What Affects Their Learning and Development? Journal of College Student Development, 52, 270-290.

Breen, L. \& Maassen, M. (2005). Reducing the incidence of plagiarism in an undergraduate course: the role of education. Issues in Educational Research, 15(1), 1-16.

Cameron, C., Deming, S. P., Notzon, B., Cantor, S. B., Broglio, K. R., \& Pagel W. (2009). Scientific writing training for academic physicians of diverse language background. Academic Medicine, 84(4), 505-510.

Cameron, J., Nairn, K. \& Higgins, J. (2009). Demystifying Academic Writing: Reflections on Emotions, Know-How and Academic Identity. Journal of Geography in Higher Education, 33 (2), 269-284.

Comas-Forgas, R., \& Sureda-Negre, J. (2010). Academic plagiarism: explanatory factors from students' perspective. Journal of Academic Ethics, 8, 217-232.

Darab, S. (2006). A preventive approach to plagiarism: an empirical study of a first-year unit for undergraduates. International Journal for Educational Integrity, 2, 3-15. 
Dysthe, O. (2007). How a reform affects writing in higher education. Studies in Higher Education, 32 (2), 237-252.

Gilmore, J., Strickland, D., Timmerman, B., Maher, M., \& Feldon, D. (2010). Weeds in the flower garden: an exploration of plagiarism in graduate students' research proposals and its connection to enculturation, ESL and contextual factors. International Journal for Educational Integrity, 6, 13-28.

Groarke, L. (2013). Informal Logic. In E. N. Zalta (Ed.), The Stanford Encyclopedia of Philosophy (Spring 2013 Edition). Stanford University. http://plato.stanford.edu/archives/spr2013/entries/logic-informal/

Gu, Q., \& Brooks, J. (2008). Beyond the accusation of plagiarism. System, 36(3), 337-352.

Gullifer, J. \& Tyson, G. A. (2010). Exploring university students' perceptions of plagiarism: a focus group study. Studies in Higher Education, 35(4), 463-481.

Hyytinen, H., Holma, K., Toom, A., Shavelson, R. J., \& Lindblom-Ylänne, S. (2014). The complex relationship between students' critical thinking and epistemological beliefs in the context of problem solving. Frontline Learning Research, 6, 1-15.

Hyytinen, H., Nissinen, K., Ursin, J., Toom, A., \& Lindblom-Ylänne, S. (2015).

Problematising the equivalance of the test results of performance-based critical thinking tests for undergraduate students. Studies in Educational Evaluation, 44, 1-8.

Doi:10.1016/j.stueduc.2014.11.001

Jurowska, J. E., \& Thompson, J. P. (2010). “Opening doors to early academic integrity" aiding the transition to and managing expectations of academic practice at university. International Journal for Educational Integrity, 8, 4-20.

Kaposi, D. \& Dell, P. (2012). Discourses of plagiarism: moralist, proceduralist, developmental and inter-textual approaches. British Journal of Sociology of Education, 33 (6), 813-830.

Keinonen, T., \& Kärkkäinen, S. (2010). University students' argumentation in science and environmental education. Problems of Education in the $21^{\text {st }}$ Century 22, 54-63.

King, P. M., \& Kitchener, K. S. (2004). Reflective Judgment: Theory and Research on the Development of Epistemic Assumptions Trough Adulthood. Educational Psychologist, 39, 5-18.

Klein, S., Benjamin, R., Shavelson, R., \& Bolus, R. (2007). The Collegiate Learning Assessment. Facts and Fantasies. Evaluation Review, 31 (5), 415-439.

Kruse, O. (2003). Getting started: academic writing in the first year of a university education. In L. Björk, G. Bräuer, L. Rienecker \& P. S. Jörgensen (Eds.), Teaching Academic Writing in European Higher Education. Studies in Writing, (pp. 29-40). Dorchrecht: Kluwer Academic Publisher.

Kuhn, D. (1999). A developmental model of critical thinking. Educational Researcher, 28, $16-25$.

Kuhn, D. (2005). Education for thinking. Cambridge, MA: Harvard University Press.

Kuhn, D., \& Weinstock, M. (2002). What is epistemological thinking and why does it matter? In B. K. Hofer \& P. R. Pintrich (Eds.) Personal epistemology: The psychology of Beliefs about Knowledge and Knowing, (pp.121-144). New Jersey: Lawrence Erlbaum Associates.

Lea, M. R., \&. Street, B. V. (1998). Student writing in higher education: An academic literacies approach. Studies in Higher Education, 23, 157-173.

Lonka, K. (2003). Helping doctoral student to finish their theses. In L. Björk, G. Bräuer, L. Rienecker \& P. S. Jörgensen (Eds.), Teaching Academic Writing in European Higher Education. Studies in Writing, ed., (pp. 113-131). Dorchrecht: Kluwer Academic Publisher. 
Löfström, E. \& Kupila, P. (2013). The Instructional challenges of Student Plagiarism. Journal of Academic Ethics, 11(3), 231-242Maclellan, E. (2004). How convincing is alternative assessment for use in higher education. Assessment \& Evaluation in Higher Education, 29, 311-321.

Mateos, M., Cuevas, I., Martin, E., Martin, A., Echeita, G., \& Luna, M. (2011). Reading to write an argumentation: the role of epistemological, reading and writing beliefs. Journal of Research in Reading, 34 (3), 281-297.

Mateos, M., \& Solé, I. (2009). Synthesizing information from various texts: A study of procedures and products at the different educational levels. European Journal of Psychology of Education, XXIV, 435-451.

Northedge, A. (2003). Enabling participation in academic discourse. Teaching in Higher Education, 8, 169-180.

Nussbaum, E. M., Sinatra, G. M., \& Poliquin, A. (2008). Role of epistemic beliefs and scientific argumentation in science learning. International Journal \& Science Education, 30, 1977-1999.

Park, C. (2003). In other (people's) words: plagiarism by university students-literature and lessons. Assessment and Evaluation in Higher Education, 28, 471-488.

Pascarella, E. T., \& Terenzini, RT. (2005). How College Affects Students, Volume 2, A Third. Decade of Research. San Francisco, CA: Jossey-Bass.

Popham, W. J. (2003). Test Better, Teach Better. The instructional Role of Assessment. Alexandria, Virginia: ASCD.

Rapanta, C., Garcia-Mila, M., \& Gilabert, S. (2013). What is meant by argumentative competence? An integrative review of methods of analysis and assessment in education. Review of Educational Research, 83 (3), 483-520.

Rodriguez, M. C. (2003). Construct equivalence of multiple-choice and constructed-response items: a random effects synthesis of correlations. Journal of Educational Measurement 40, 163-184.Sandoval, W. A. (2009). Conceptual and epistemic aspects of students' scientific explanations. Journal of the Learning Sciences, 12, 5-51.

Shavelson, R. J. (2010). Measuring college learning responsibly: Accountability in a new era. Stanford, CA: Stanford University Press.

Shaw, E. J., Mattern K. D., \& Patterson, B. (2011). Discrepant SAT critical reading and writing scores: implications for college performance. Educational Assessment, 16, 145163.

Siegel, H. \& Biro, J. (1997). Epistemic Normativity, Argumentation, and Fallacies. Argumentation, 11, 277-292.

Simon, S., Erduran, S., \& Osborne, J. (2006). Learning to teach argumentation: research and development in the science classroom. International Journal of Science Education, 28 (23), 235-260.

Statistics Finland. (2012). Adult education of educational institutions in 2011. https://www.tilastokeskus.fi/til/oaiop/2011/oaiop_2011_2012-12-14_tie_001_en.html

Street, B. (2004). Academic literacies and the 'new orders': implications for research and practice in student writing in higher education. Learning and Teaching in the Social Sciences, 1(1), 9-20.

Sutherland-Smith, W. (2005). Pandora's box: academic perceptions of student plagiarism in writing. Journal of English for Academic Purposes, 4, 83-95.

Toulmin, S. E. (1958). The Uses of Argument. Cambridge University Press.

Tynjälä, P., Mason, L., \& Lonka, K. (Eds.). (2001). Writing as a Learning Tool. Integrating Theory and Practice. Studies in Writing. Dorchrecht: Kluwer Academic Publisher.

Valentine, K. (2006). Plagiarism as literacy practice: Recognizing and rethinking ethical binaries. College Composition and Communication, 58(1), 89-109 
Walker, J. (2010). Measuring plagiarism: researching what students do, not what they say they do. Studies in Higher Education, 35 (1), 41-59.

Walton, D. N. (1990). What is reasoning? What is an argument? The Journal of Philosophy, 87 (8), 388-419.

Walton, D. N. (1995). A Pragmatic Theory of Fallacy. Tuscaloosa, AL: University of Alabama Press.

Ylijoki, O-H. (2000). Disciplinary cultures and the moral order of studying: A Case-study of four Finnish university departments. Higher Education, 39, 339-369.

Ylijoki, O-H. (2001). Master's thesis writing from a narrative approach. Studies in Higher Education, 26, 21-34. 


\section{Performance task: Crime Reduction}

Introductions: You will have 90 minutes to complete this task. This task will ask you to analyze a collection of different types of information. You will then use your analysis to prepare answers to a series of questions. Although you may not be familiar with some of the topics covered, you should be able to prepare appropriate answers by carefully using and thoughtfully reflecting on the information given to you. Your answers should clearly state what you mean. Please do your best.

Role: You are a consultant to Mayor Stone. Pat Stone is running for reelection as mayor of Jefferson, a city in the state of Columbia.

Scenario: Mayor Stone's opponent in this contest is Dr. Jamie Eager. Dr. Eager is a member of the Jefferson City Council. Dr. Eager made the following three arguments during a recent TV interview.

Task: Mayor Stone has asked you to prepare a memo that analyzes the strengths and limitations of each of Dr. Eager's three main points, including any holes in those arguments. Your memo also should contain your conclusions about each of Dr. Eager's three points, explain the reasons for your conclusions, and justify those conclusions by referring to the specific documents, data, and statements on which your conclusions are based. To do so, please answers the four questions that follows, using the documents provided.

You are provided with the following documentation:
A: Investigator's Memo
E. Crime Statistics
B: Newspaper Story
F: Dr. Eager's Chart
C: Police Tables
G: Research Abstracts
D: Research Report

Note: Copyright (C) 2014 Council for Aid to Education. All rights reserved. Reprinted with permission from Council for Aid to Education.

Figure 1. An example of a CLA performance task. 


\section{Research questions}

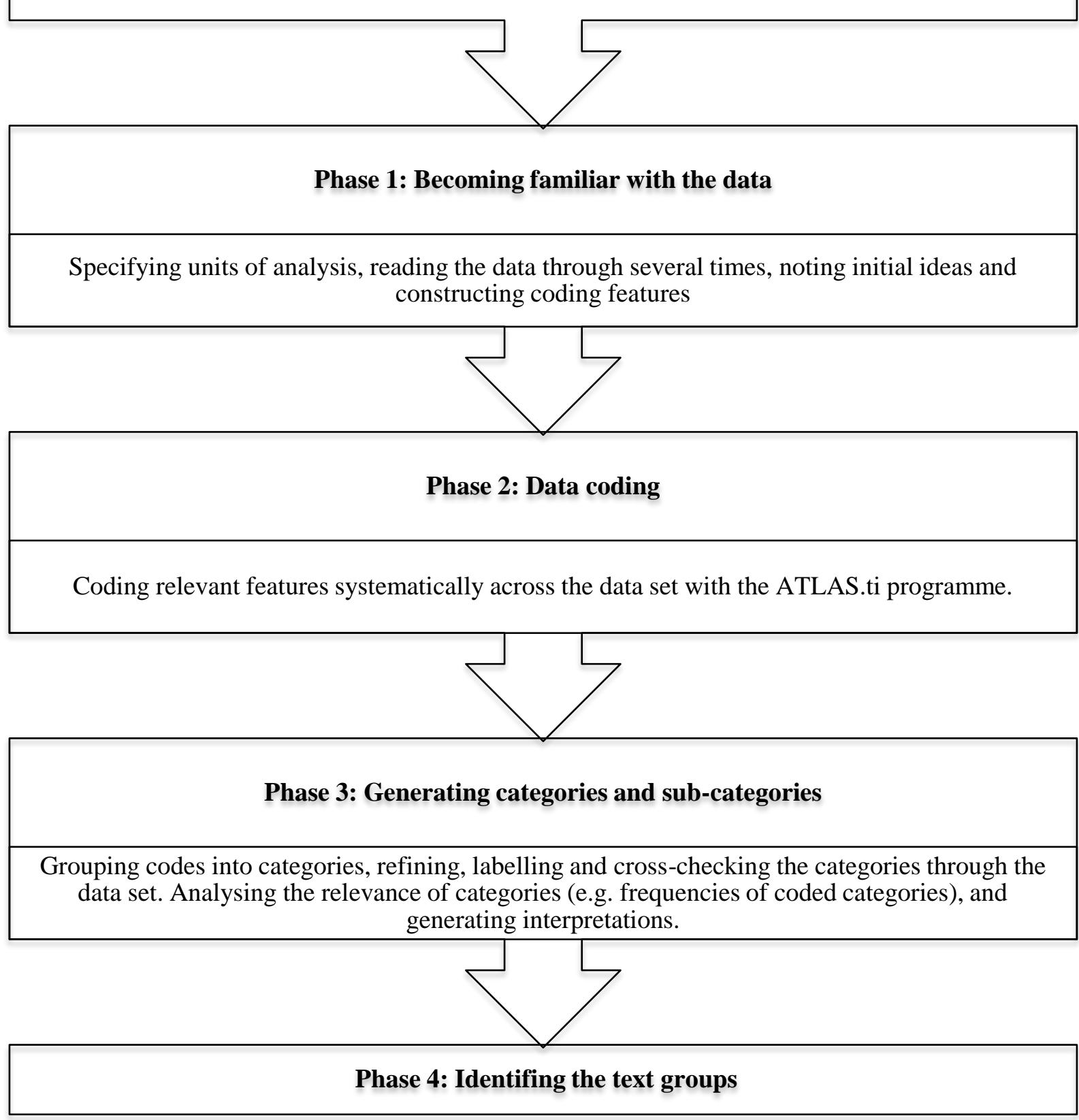

Figure 2. Phases of the analysis. 
Table 1. Categories and sub-categories of problems in argumentation and writing.

\begin{tabular}{|c|c|c|}
\hline Code & Sub-category & Category \\
\hline \multirow{9}{*}{$\begin{array}{l}\text { Problems in } \\
\text { argumentation }\end{array}$} & $\begin{array}{l}\text { Conclusion is missing } \\
\text { Rationales/ reasons are missing }\end{array}$ & Unclear Argument \\
\hline & Student provided a single reason & \\
\hline & $\begin{array}{l}\text { Student provided unconnected } \\
\text { list of facts as rationales (reasons } \\
\text { are not explained or elaborated) }\end{array}$ & $\begin{array}{l}\text { Presenting isolated } \\
\text { fact(s) as rationale(s) }\end{array}$ \\
\hline & $\begin{array}{l}\text { Student provided unconnected } \\
\text { list of sources as rationales }\end{array}$ & \\
\hline & Hasty generalisation & \multirow{5}{*}{$\begin{array}{l}\text { Incorrect argument/ } \\
\text { fallacy (conclusion is } \\
\text { inconsistent with } \\
\text { reason) }\end{array}$} \\
\hline & Irrelevant conclusion & \\
\hline & $\begin{array}{l}\text { Correlation proves causation } \\
\text { Appealing to probability }\end{array}$ & \\
\hline & Appealing to authority & \\
\hline & Appealing to tradition & \\
\hline \multirow{5}{*}{$\begin{array}{l}\text { Problems in } \\
\text { paraphrasing }\end{array}$} & \multirow{2}{*}{$\begin{array}{l}\text { The text is the same as the } \\
\text { original }\end{array}$} & Copy without source \\
\hline & & Copy with source \\
\hline & \multirow{2}{*}{$\begin{array}{l}\text { Sources are cited, but the text is } \\
\text { almost the same as in the original }\end{array}$} & $\begin{array}{l}\text { Patchwork } \\
\text { paraphrasing }\end{array}$ \\
\hline & & Poor paraphrasing \\
\hline & & $\begin{array}{l}\text { Conclusions disguised } \\
\text { as one's own }\end{array}$ \\
\hline
\end{tabular}


Table 2. Frequency of categories in each text group.

\begin{tabular}{|c|c|c|c|c|c|c|}
\hline & \multicolumn{6}{|c|}{ Text groups } \\
\hline & \multicolumn{2}{|c|}{$\begin{array}{c}\text { Superficially processed } \\
\text { texts } n=46(33 \%)\end{array}$} & \multicolumn{2}{|c|}{$\begin{array}{l}\text { Patchy texts } \\
\mathrm{n}=73(53 \%)\end{array}$} & \multicolumn{2}{|c|}{$\begin{array}{c}\text { Thoroughly processed } \\
\text { texts } n=19(14 \%)\end{array}$} \\
\hline & $\begin{array}{l}\text { Number of } \\
\text { students' } \\
\text { answers* }\end{array}$ & $\begin{array}{l}\text { Frequency } \\
\text { of coded } \\
\text { category** }\end{array}$ & $\begin{array}{c}\text { Number of } \\
\text { students' } \\
\text { answers* }\end{array}$ & $\begin{array}{l}\text { Frequency } \\
\text { of coded } \\
\text { category** }\end{array}$ & $\begin{array}{l}\text { Number of } \\
\text { students' } \\
\text { answers* }\end{array}$ & $\begin{array}{c}\text { Frequency } \\
\text { of coded } \\
\text { category** }\end{array}$ \\
\hline \multicolumn{7}{|l|}{$\begin{array}{l}\text { Problems in } \\
\text { argumentation }\end{array}$} \\
\hline $\begin{array}{l}\text { Unclear } \\
\text { argumentation }\end{array}$ & $31(67 \%)$ & 58 & $50(68 \%)$ & 69 & $4(21 \%)$ & 4 \\
\hline Isolated fact & $19(41 \%)$ & 31 & $17(23 \%)$ & 24 & $4(21 \%)$ & 4 \\
\hline $\begin{array}{l}\text { Fallacy /incorrect } \\
\text { argument }\end{array}$ & $29(63 \%)$ & 70 & $54(74 \%)$ & 89 & $9(47 \%)$ & 12 \\
\hline \multicolumn{7}{|l|}{$\begin{array}{l}\text { Problems in } \\
\text { paraphrasing }\end{array}$} \\
\hline Copy without source & $6(13 \%)$ & 8 & $9(12 \%)$ & 9 & 0 & 0 \\
\hline Copy with source & $26(57 \%)$ & 53 & $30(41 \%)$ & 65 & $3(16 \%)$ & 5 \\
\hline $\begin{array}{l}\text { Patchwork } \\
\text { paraphrasing }\end{array}$ & $4(9 \%)$ & 4 & $2(3 \%)$ & 2 & $1(5 \%)$ & 2 \\
\hline Poor paraphrasing & $39(85 \%)$ & 118 & $60(82 \%)$ & 140 & $11(58 \%)$ & 18 \\
\hline $\begin{array}{l}\text { Conclusions } \\
\text { disguised } \\
\text { as one's own }\end{array}$ & $4(9 \%)$ & 4 & $6(8 \%)$ & 9 & 0 & 0 \\
\hline
\end{tabular}

*Note: The frequencies refer to the number of answers.

** Note: These frequencies refer to the number of times the particular category was identified in the data. 
Table 3. Educational background and gender distribution in each group.

\begin{tabular}{lccc}
\hline & \multicolumn{3}{c}{ Groups } \\
\cline { 2 - 4 } Educational background & $\begin{array}{c}\text { Superficially } \\
\text { processed texts }\end{array}$ & Patchy texts & $\begin{array}{c}\text { Thoroughly } \\
\text { processed texts }\end{array}$ \\
\hline $\begin{array}{l}\text { General upper secondary } \\
\text { education }\end{array}$ & $11(24 \%)$ & $18(25 \%)$ & $5(26 \%)$ \\
$\begin{array}{l}\text { Vocational upper secondary } \\
\text { education }\end{array}$ & $11(24 \%)$ & $8(11 \%)$ & $3(16 \%)$ \\
Polytechnic degree & $15(32 \%)$ & $30(41 \%)$ & $5(26 \%)$ \\
University degree & $9(20 \%)$ & $17(23 \%)$ & $6(32 \%)$ \\
\hline Total & $46(100 \%)$ & $73(100 \%)$ & $19(100 \%)$ \\
\hline Gender & Women 41(89\%) & Women 63(86\%) & Women 13(68\%) \\
\hline
\end{tabular}

Note: The frequencies do not differ statistically significantly from each other at the $p<.05$ level. 